\title{
Interpersonal Wishes and Fears with Regard to Internalized Attachment Figures: Differing Focus of Two Case Formulation Methods that use SASB
}

\author{
KENNETH L. CRITCHFIELD, a,b JULIA DOBNER-PEREIRA, ${ }^{a}$ \& \\ ELIZA STUCKER ${ }^{\text {a }}$
}

\author{
a James Madison University \\ ${ }^{\mathrm{b}}$ Correspondence regarding this article should be sent to: Kenneth L. Critchfield, 7401, Johnston Hall, Rm. 219, 70 \\ Alumnae Drive, Harrisonburg, VA 22807. \\ Email: critchk1@jmu.edu
}

\begin{abstract}
This commentary is organized in parallel with Westerman's (2021b) comparison to include focus on (1) the formulation methods used by IRT and Interpersonal Defense Theory, and then (2) their treatment implications. In each major section, comments center first on comparison of the approaches in general, and then turn to a focus on the details of Sharon's case. In sum, we wish to underscore the need for continued empirical work in both IRT and Interpersonal Defense Theory traditions as ways to advance our field. We see each method as offering a different scope and focal areas of concern. With a mind toward the advancement of research and application along both lines of thought, our commentary provides an overview of how we see areas of alignment, divergence, and their potential meaning for theory and practice. The two methods share a great deal in terms of assumptive worldviews, prioritization of relational material, and even specific measurement methodology (SASB). Where the methods diverge, we believe it is primarily because they seek answers to different kinds of questions.
\end{abstract}

Keywords: wishes; fears; reliability; internalized figures; Interpersonal Reconstructive Therapy (IRT); Interpersonal defense Theory; case study; clinical case study

This commentary offers reflections on primary articles (Critchfield, Dobner-Pereira, \& Stucker, 2021; Westerman, 2021a) demonstrating how IRT and Interpersonal Defense Theory each formulate clinical phenomena, with shared focus on the case of Sharon. To aid readers in following our separate viewpoints, the present commentary is organized in parallel with Westerman's (2021b) comparison to include focus on (1) the formulation methods used by IRT and Interpersonal Defense Theory, and then (2) their treatment implications. In each major section, comments center first on comparison of the approaches in general, and then turn to a focus on the details of Sharon's case. We do not seek to be exhaustive in our comparison. A great deal more about each approach to formulation, their supporting research, and implications for treatment are available elsewhere. Ultimately, we see the empirical work in both IRT and Interpersonal Defense Theory traditions to be important and can possibly be articulated together, although they each take up separate concerns and are at differing stages of empirical evaluation 
in terms of the reliability of observed phenomena and validation of underlying mechanisms and constructs. Our commentary provides an overview of how we see areas of alignment, divergence, and their relevance to theory, research, and practice.

\section{COMPARING CASE FORMULATIONS}

\section{Comparing the Two Approaches to Case Formulation in General}

\section{Commonalities}

Interpersonal Defense Theory and IRT are near neighbor construct systems that share a great deal of intellectual history, tradition, and infrastructure. A core strategy of each method is to position relational processes at the center of clinical formulation, which in turn shapes how patient personality, presenting problems, and the process and outcome of therapy are approached. Interpersonal Defense Theory offers a method showing how certain defense mechanisms, conceived of as interactive social processes driven by competing wishes and fears, are observable and measurable in session material. As will be explained in some detail later, IRT also implicates concepts of interpersonal wish, fear, and related forms of defense as part of its approach to case formulation. IRT and Interpersonal Defense Theory are thus alike in taking on the challenge of operationalizing psychodynamic processes and rendering them empirically testable. Such work is hard fought, since these kinds of theories embrace a complex worldview in which behavioral consistency emerges in context-specific ways that reflect motivational factors as well as the individual's learning history for similarly perceived environments.

Both methods assume that human behavior is motivated, seeks adaptation, and is ultimately understandable based on some variation of an individual's learning history in light of wishes, fears, and interactive / transactional opportunities of the present. Both methods invoke a set of related motivational factors (conscious or unconscious) that are inferred from evidence of organization within the behavioral patterns that constitute their primary data sources. While Interpersonal Defense Theory and IRT formulations differ in their emphasis, each method involves some consideration of what is narrated about relationships in the content of conversations and what is enacted in the here-and-now process of interpersonal situations (including with therapists). Use of Structural Analysis of Social Behavior (SASB: Benjamin, 1979) as a descriptive model grounds both methods. The methods thus prioritize relatedness, interactivity, and motivational states as they shape processes of an individual's life in and out of psychotherapy.

\section{Divergences Involving Goals, Frames, and Levels of Analysis}

Divergences between IRT and Interpersonal Defense Theory reflect differing goals, concerns, and strategies employed by each method. A number of these differences are deeply rooted in their respective theories and worldviews. A key set of divergences involves ways in which wishes, fears, and defenses are framed in each system. In general terms, Interpersonal Defense Theory's formulation provides a template that explains how interpersonal processes in the present can result in stable, but problematic, patterns that are a function of an individual's 
K.L. Critchfield, J. Dobner-Pereira, \& E. Stucker

Pragmatic Case Studies in Psychotherapy, http://pcsp.libraries.rutgers.edu

Volume 17, Module 1, Article 6, pp. 85-103, 04-19-21 [copyright by authors]

relational wishes and fears derived in large part from careful inspection of sequential, momentby-moment patterns of relating in the present.

\section{Wishes, Fears, and Defense Mechanisms in IRT}

Benjamin (1995) provides an overview of how defense mechanisms relate to wishes, fears, and healthy versus unhealthy relating within the space defined by the SASB model. While wishes and fears are not a major focus of IRT case formulation, Benjamin's thoughts along these lines would later inform IRT. The basic premise is that defenses play a number of important roles in the interpersonal realm. This basic idea is not new. Benjamin's chapter is part of a larger volume focused on ego defenses that offers a range of proposed methods for understanding defensive processes through the lens of recurrent cycles of interpersonal behavior between the patient and others (e.g. Horowitz \& Stinson, 1995; Dahl, 1995). Cyclic interpersonal notions of personality and transference dynamics have also been framed by Hans Strupp (e.g., Cyclic Maladaptive Pattern, CMP: Strupp \& Binder, 1984), Lester Luborsky (e.g., Core Conflictual Relationship Theme, CCRT: Luborsky \& Crits-Christoph, 1990) and their colleagues as key features of their case formulation methods. Research conducted across approaches supports the premise that defense mechanisms can be viewed through an interpersonal lens. Benjamin (1995) uses the SASB model, especially the Attachment Group (AG) and Disrupted Attachment Group (DAG) regions of the SASB model to illustrate adaptive versus maladaptive uses of defense.

As a reminder, AG involves behaviors on the right side of the SASB model, which are indicative of secure attachment. This region is characterized by warm affiliation, moderate degrees of interdependence, and reciprocity of focus on other and self in normative social contexts. By contrast, DAG involves a range of behaviors that include disaffiliation/hostility expressed outwardly toward others, or reactively engaged in relation to them. It also involves extremes of interdependence versus independence implemented without warmth (i.e., poles along SASB's vertical axis). The basic premise is that all defenses serve to either enhance wishes or diminish fears. And so, if what is wished for leads to a baseline of AG interactions then the associated defense has led to an adaptive/normal outcome. However, if the wish leads to a baseline of DAG behaviors, then the outcome is maladaptive/pathological. This basic distinction between regions of the SASB model is invoked in IRT as way to define therapy goals. Thus, fears and defenses that lead to DAG behavior are problematic, but those that lead to AG are conducive to normal functioning. The key discernment is whether wishes, fears, and associated defensive processes produce adaptive or maladaptive outcomes in relation to self or others.

The idea that perceived signals of safety and threat (related to wishes and fears) are linked to early learning in attachment relationships is a second key distinction that seems critical to us when considering divergences between IRT and Interpersonal Defense Theory. In the same chapter, Benjamin (1995) emphasizes that the wishes and fears of greatest concern are those that are linked to internalized attachment figures. Benjamin specifically illustrates how wishes and fears may use several categories of defensive operations, some deployed externally as interpersonal behavior, and others internally as distortions of various kinds. All are conceived of as being oriented to connections with Important Persons or their Internalized Representations (IPIRs): "pathological defenses are often the result of attachment to destructive IPIRs" (p. 62). 
K.L. Critchfield, J. Dobner-Pereira, \& E. Stucker

Pragmatic Case Studies in Psychotherapy, http://pcsp.libraries.rutgers.edu

Volume 17, Module 1, Article 6, pp. 85-103, 04-19-21 [copyright by authors]

She also notes, "In the long run, it is better if there are no distortions or blockages because attachment is better supported by the real-life data stream if no distortion is required" (p. 67). These concepts remain important in IRT theory as articulated more recently by Benjamin (2018) in that the underlying theory of psychopathology and treatment often involves the need to "recue" maladaptive perceptions of safety and threat learned with important others in exchange for more adaptive views that are responsive to present circumstances.

Thus, from the point of view of IRT theory, wishes and fears of primary concern are not necessarily about a current partner in an interaction unless that interaction has salience to the internalized attachment relationship. For example, if a patient has repeatedly heard and internalized from loved ones that they are a burden and to blame for family problems, then it will be hard for that same patient to hear a therapist's praise about recent attempts to set boundaries and assert needs with a romantic partner. The idea that this feedback would be difficult because it relates to a set of belief structures, or schema, that provide a template for navigating current situations seems shared across IRT and Interpersonal Defense Theory. What IRT theory adds emphasis to is the idea that for many patients, the nature of schema is such that earlier attachment relationships are currently active inside the mind of the individual. The circumstance is like having a therapy session with the loved one present and listening. When the therapist in our example conveys affirmation, the patient's connection to that loved one may be challenged. Subsequent responses may demonstrate loyalty to the views of the internalized other person as a way of staying aligned with them, to seek security from them.

Optimally, an IRT therapist would be sensitive to this possibility and work to help the patient have and voice their own view, much as could occur in a family therapy session, perhaps enhanced by variations of two-chair technique, or role plays to help evoke and identify the "voice" of the IPIR directly in session. Clarity about who the wishes and fears are in relation to could help such a patient choose for themselves how to evaluate their own present behavior rather than feeling forced to choose between siding with either the voice of their therapist or their IPIR. A patient evoked this idea recently, challenging the therapist's intervention in plain terms "What makes your opinion of me more accurate than theirs? They have known me longer, and therefore know me better ... There are also more of them and they all have the same opinion of me that significantly differs from yours. You can't know the true me the way they do. Why should I believe you over them?" (Critchfield, Dobner-Pereira, Panizo, \& Drucker, 2018). The IRT lens acknowledges that the felt need for connection and alignment with an internalized attachment figure is often powerful enough to override input from current others who do not yet have the same status or credibility. The issue is thus not simply a matter of revising problematic residuals of past learning that are now applied reflexively with current relational partners (e.g., a therapist). It is often also a matter of addressing the here-and-now relationship experienced with the internalized loved one and wresting enough distance from that internalized figure to allow updates and new learning to take greater hold.

Interpersonal Defense Theory appears to frame wishes and fears a bit differently, as learned and practiced in the past, but now having primary significance in relation to new relational partners, including therapists. We believe the difference is of great importance for decision-making around interventions. Therapists are often salient to "family in the head," as 
they are typically perceived as authority figures who have potential to align with or threaten the views of IPIRs. In addition, IRT research has demonstrated that Recapitulation (i.e,. the copy process that involves interacting with current others as if the IPIR is still present and in charge) is a common occurrence (Critchfield et al, 2015; Critchfield \& Benjamin, 2008, 2010). Given this finding, it is expectable that familiar repetitions of historical themes would occur between patients and therapists. This view is held by both theories. Where the distinction becomes relevant is whether the active relation to internalized attachment figures needs to be addressed in some form to bring about change. We believe that the answer likely has to do with the details of what a given patient has internalized, coupled with their relative balance of Green versus Red. It is a question that is open to empirical investigation if the issue is framed clearly enough. We will return to the issue of how IRT research approaches this issue in a later section.

\section{Other Key Differences}

Scope of the Formulation and Connection to a Broader Treatment Approach. Interpersonal Defense Theory is framed as way of understanding and predicting regularities in the unfolding of certain relational processes in real time. When tracked in the therapeutic relationship, we agree with Westerman (2021a) that these patterns likely have relevance to presenting symptoms and problems, derive from earlier learning, and have implications for treatment. Beyond this, the approaches differ in that IRT case formulation has as part of its task to precisely specify links between copied figures and a patient's current symptoms and problems. From there, the case formulation serves as a template for tracking patient patterns across multiple settings (what they are, where and with whom they were learned, and what they are for in the present), their links to symptoms, and associated choices the patient has for new learning in ways that have process and content elements. The formulation brings focus to repeating themes across the attachment history throughout the psychotherapy process, and a frequent implication is that there is a related need to come to terms with the internalized figures to resolve symptoms and/or stalled progress.

\section{Collaborative Process and the Role of In-Session Sequential Interaction. The IRT} formulation serves as a kind of schematic, developed through a collaborative interview process early in therapy in which patients can say for themselves whether it makes sense, whether they recognize the copy process patterns, and whether the GOL hypothesis makes sense to them. In IRT, if the patient does not agree with the formulation, then it is not correct and needs revision. In this sense, the IRT approach to formulation and treatment is consistent with principles of trauma-informed care. It is not clear that the same kind of collaborative understanding is essential for Interpersonal Defense Theory, which appears to involve a process of transcript analysis that is conducted separate from conversation with a patient. In IRT, the case formulation method is designed to be efficient for most clinical contexts. It also has an alternative or supplementary methodology that involves strategic use of the SASB-based Intrex Questionnaires.

While IRT methods do not require detailed review of transcripts, process analyses have been conducted as part of past research efforts, and so have some bearing on our current comparison. IRT-relevant focus on here-and-now therapeutic processes have been illustrated in 
prior research exploring aspects of formulation. As will be noted in a section that follows, Karpiak and Benjamin (2004) have demonstrated the effect that therapist comments have when following adaptive/Green versus maladaptive/Red patient comments. Recent sequential analysis of IRT treatments suggests possibility that therapists higher in IRT adherence respond in less contingent ways to patient status as Red or Green, tending to offer a consistent balance of friendly relatedness (Affirm and Protect) when compared to low adherent therapists (Critchfield, Stucker, Bonilla, Mischinski, \& Benjamin, 2020). While this level of analysis is rarely undertaken in clinical practice, it is often felt intuitively, can be observed in supervisory review of recorded sessions, and has potential to inform efforts at deliberate practice.

Specificity of the Evidence Base Linking Formulation to Other Clinical Elements. Benjamin invokes the "specificity hypothesis" in two ways. The first is that patterns in early history often can be detected as patterns in current relationship using very precise definitions and matches between SASB profiles. Empirical work has established these links, including evaluation of base rates, methods, and parameters for detecting copy process in clinical and normal samples (Conroy \& Pincus, 2006; Critchfield \& Benjamin, 2008, 2010). IRT also predicts specific linkage between symptoms/clinical problems and SASB-defined constellations of interpersonal patterning involving input from others, responses of the self, and self-treatment. The theory linking specific interpersonal patterns to clinical symptoms and problems has been a major focus of Benjamin's work and includes details about how interpersonal profiles relate to clinical symptoms such as anger, anxiety, and depression (Benjamin, 2018) as well as each of the DSM personality disorders. Recent work to demonstrate the reliability, discriminability, and sensitivity of these links is available in Critchfield, Benjamin, and Levenick (2015).

Approach to Understanding Conflict and "The Self". IRT and Interpersonal Defense Theory appear to have different approaches to the idea of internal conflict. In IRT, the self is not understood to be unitary in nature. The internal conflict of most salience derives from the two parts of the self posited in IRT that are referred to as Red and Green. These two parts of the self may have different wishes and fears regarding people in the present, and so the manifestation of wishes and fears can look quite different depending on a patient's state. For example, Green would typically involve normative, reality-based wishes and fears oriented to a healthy attachment model (i.e. the right side of SASB in relation to both self and others). Friendly, reciprocal, context-appropriate relating is generally wished for, while forms of hostility and extremes of distance and closeness are likely feared. Any defenses employed in that state would look prosocial, normative, and adaptive.

Meanwhile, Red would have wishes and fears that are cued (or miscued) by whatever patterns were salient in the individual's attachment-based learning history pertaining to safety and threat (Benjamin, 2018). In IRT, the potential is high for both these parts of the self to be present in interactions with another person, including the therapist, depending on what templates and associations regarding safety and threat are being called up. An example might be a wish to be "understood and accepted for who I really am" with someone in the present, coupled with a wish to remain loyal to father's view that "you're an idiot who doesn't have anything useful to say." The therapeutic approach in IRT would take up the challenge of how to pursue Green ways of being, given these two wishes. If the wish to be understood and accepted is reasonable to the 
K.L. Critchfield, J. Dobner-Pereira, \& E. Stucker

Pragmatic Case Studies in Psychotherapy, http://pcsp.libraries.rutgers.edu

Volume 17, Module 1, Article 6, pp. 85-103, 04-19-21 [copyright by authors]

context (i.e., Green), then it could be supported, while the wish to be loyal to father through selfnegation is not. If both wishes are applied in ways that are maladaptive, then an IRT goal might include the possibility of giving up both of these wishes in exchange for comfortably being "who I really am."

Some of our current IRT research involves detailed coding of transcripts, including momentary assessment of a patient's states as Red or Green alongside SASB codes of the therapy interaction (Critchfield et al., 2020). The Red/Green distinction (cued to the individual formulation) appears reliable in our work so far, and may be an interesting point for research that bridges across theories to see whether the observed patterns of interaction described by Interpersonal Defense Theory tend to occur more often in Red versus Green states.

\section{Comparing Formulations for Sharon's Case}

It is difficult to comment on the internal workings of the Interpersonal Defense Theory formulation for Sharon. Our impression is that Westerman (2021a) described the general process and then provided conclusions about Sharon's case. The specific transcript material from which these conclusions derived was not presented. As a result it was also unclear to us how certain features of the historical data were selected for emphasis and how factors unique to the therapeutic context, such as the power differential in their respective roles and personal factors such as gender, might shape interpretation of therapeutic patterns in the Interpersonal Defense Theory framework. As a result, it is not easy to see where points of connection may be at the level of selecting and parsing specific observations.

\section{Collaboration with Patients in IRT Formulation Work}

The different presentational styles of the two formulations of Sharon may suggest a difference in the approach to validation that each theory pursues or values. The ethic in IRT research and practice is to provide the basis for formulation in terms of showing specific quotes or patient descriptions of events and their implications for copy process, symptom meaning, and so on. For example, within the constraints allowable by a paper of its type, we attempted to show readers the nature of Sharon's comments and narratives alongside our SASB-based characterizations of them. Our hope is to make clear how the copy processes, links to symptoms, and hypotheses about GOL may be sensible given Sharon's statements. This approach to formulation writing follows from the IRT approach to clinical work, which including collaborative review of patient statements and characterizations as well. Underlying it is the belief that the formulation is not valid if the patient does not agree with it. From Westerman's description, we are not certain how the formulation process in Interpersonal Defense Theory might be communicated with patients.

Replicability and Reliability Concepts in Formulation Research. Our research focused on the properties of IRT case formulations demonstrates the approach we recommend for validation efforts. The analysis proceeds at the level of specific observations or propositions in a formulation, as independently assessed by different coders or teams. For example, our investigation of the reliability properties of IRT formulation involved two teams of trained IRT clinicians, working independently in different US States, to watch the same interview and 
develop team-based consensus formulations. These formulations were then compared for agreement about the key attachment figures, copy processes, and the links for each of these to specific symptoms (the three-way linkage of key figures to symptoms through a specific copy process was also assessed). Reliability of interpersonal patterns constituting each copy process was also examined through use of SASB. Each comparison required evaluation of the evidence marshalled in support of each link to determine whether the teams agreed using a template that required the formulator to lay out the evidence supporting each assertion. The template has since proven very useful for training clinicians to use the method. The resulting reliability in each measured domain was strong (Critchfield et al, 2015). We separately developed a procedure, also found useful for training, in which formulations limited to only copy processes and SASB codes had to be matched by raters to their source interviews. This work demonstrated that agreement did not simply derive from stereotyped application of the formulation template, but instead reflected unique individual patterning required for tailored treatment.

We believe that this level of detailed inspection, analysis, and testing is critical for establishing validity and replicability of any formulation method. While the work can laborious, the level of detail and attention is crucial to empirical validation as it seeks to validate internal logic and consistency. Our value here is to develop a method that is reliable, uniquely identifies individual patients, has clear and transparent rules for decision-making about central propositions, and can be applied directly by practitioners. When use of the formulation translates to outcomes, this kind of internal validity work helps reassure that the method not only works, but works in the way it proposes.

\section{Collaborative Evaluation of Formulation Evidence in Clinical Work. As noted,} transparency about the process of formulation extends to the therapeutic process in IRT as well. The ways in which an IRT therapist discusses how symptoms "make sense" in light of interpersonal patterns and internalized learning is frank, collaborative, and based on the language and perceptions offered by the patient. Language used in the Interpersonal Defense Theory formulation seemed harsh to us, with characterizations of her as "stubborn" and "intransigent", or that she "provokes" and "baits" others. We have certainly worked with patients who might own such terms, or use similar ones to describe themselves, but are unsure how they would land with Sharon. In any case, in IRT work the client would have to agree that whatever is offered constitutes a fair characterization so that it can form the basis for working together going forward.

Relatedly, one of the challenges we have in approaching Sharon's case is that she was not herself available to say yea or nay to the various propositions we make in her IRT formulation. Our process was to find descriptions of her early history in her intake materials and in her insession descriptions of those relationships so that we could at least have her own words to characterize her interpersonal situations and self-concepts. This is as close as we could come to our usual collaborative process. In a more typical IRT setting, Sharon would be able to comment and provide feedback directly about specific formulation elements, their accuracy, and their potential salience in her life. We acknowledge this in part by identifying areas where we were less certain or made inferences needing more input from Sharon to be considered valid. 


\section{Differences in SASB-coded perceptions of interactive transcript material}

Translating the SASB codes from their Full Model version into the Simplified Cluster Model, the Interpersonal Defense Theory formulation for Sharon includes the following: Her relational wish is to be Emancipated (and/or Affirmed $5^{1}$ ) by her therapist for being Separate. However, she also fears the same stance on her part will lead to Ignore. These codes are interesting given that the wishes and fears are very close to one another on the SASB model, likely making it difficult for an individual to discern between them. In a rough sense they translate into a desire to be free to be herself and given a lot of room by others, all the while fearing their neglect. According to the Interpersonal Defense Theory formulation, she engages in behavioral sequences that have the net result of successfully avoiding the fear with her therapist (and likely others more generally), but in a way that entails never realizing the wish.

Westerman provides an illustrative transcript segment, including a characterization of its various elements in SASB-based terms. Due to time constraints, we were not exhaustive in our comparison, but coded the first part of the transcript offered for comparison. We found that we held a divergent views of Sharon's data (see Table 1). In the passage shown there, we primarily see Sharon as Trusting her therapist, meaning that she is focused on her own needs and concerns (i.e., Focus on Self), and moderately submissive/reliant as well as friendly in her stance. On the SASB model, this places her in the lower right region. As her therapist does not respond as she wishes, she supplements this stance of Trust with Affirm and Submit in an apparent effort to be more persuasive about the desired complementary input (Protect) from him (i.e., through appeasement).

We see Sharon's requested input from the therapist as being for friendly influence focused on the details of her letter. This desired input would be coded in the lower right of the SASB model as Protect. However, the therapist does not do this, primarily asserting his views as being separate from her (Separate), and ultimately refusing her request (Ignore). He is not completely disconnected, however. He also Affirms her ability to figure things out herself, and soon shifts to what we perceive as a complex message involving both sensible analysis and a blaming critique of her approach (Protect + Blame) as she persists in asking for his input. Overall, we see the therapist as withholding and offering a range of mixed messages, to which Sharon engages in a number of indirect attempts at persuasion to get her desired input. We agree with Westerman that the therapist could, and likely should, have simply offered his opinion and gone on to process its meaning in a much more collaborative way.

Contrasting our view, Sharon is coded by Westerman (2021a) as taking neutral distance from her therapist to assert herself separately and "take a stand" (i.e. Separate). Codes provided for the therapist are highly enmeshed: focused on Sharon with a good deal of influence that is neither hostile nor friendly (Control), along with instances that are more moderate and warm (Protect). The moments of SASB-coded agreement between our views occur in the brief moments when Sharon Submits.

If we accept the Interpersonal Defense Theory formulation coding of Sharon's wishes and fears, then our own view of the transcript leads us to conclude that Sharon did receive at 
least some version of both her feared (Ignore) and her wished for (Affirm) response from her therapist. However, since Sharon's stance of Trust pulls for something quite different than her proposed wish and fear, our divergent view of the interaction can still be understood as being in support Interpersonal Defense Theory principles. Sharon doesn't seem to risk much of herself by asking for advice about Jeff's letter and so does not risk abandonment in any deep way. She instead pulls for its SASB-defined opposite: Protect. In a short time, her therapist stops distancing and instead becomes engaged, but through use of interpretation and a critique of her help-seeking. She thus avoids her fear, and also avoids her wish. What we note along the way is that we see the process as occurring through a different route than was narrated by Westerman (2021a). We also wonder about possible presence of a different wish for therapeutic input than was offered in the formulation, since the explicit bid was for Protect rather than Emancipate or Affirm. It is possible, of course, that the other wish was still present but not expressed.

Differences of the kind noted here are subtle, but in some circumstances can have profound implications for process and outcome of a therapy. For example, Ulberg and colleagues provided a SASB-coded, transcript-based inspection of transference for a single, poor outcome case (Ulberg, Amlo, Critchfield, Marble, \& Høglend, 2016). The therapist in their case appeared to offer inaccurate transference reflections about the nature of the patient's fears relative to interactions with the therapist. Inaccuracies of this kind have been associated with poorer outcomes in other samples as well (Crits-Christoph et al, 2010).

Use of SASB as a shared measurement model seems to underscore that we may ultimately view this interaction through very different lenses even at the level of observing specific instances of transcribed behavior. SASB coding is difficult, but it can be done reliably as has been shown in prior research (Benjamin \& Cushing, 2000; Benjamin, Rothweiler, \& Critchfield, 2006). Differences might reflect missteps in procedure, analyzing only a small sampling of behavior, or use of transcript (our circumstance) versus the full video-recording (Westerman's circumstance). A more interesting possibility is that differences might also be traceable to the theoretical perspectives themselves. We each might, for example, prioritize different elements of context or implicit knowledge of other formulation elements to help assess the underlying meaning and dimensionality of the ongoing interaction.

\section{Relationship of the Illustrative Transcript Sequence to IRT Formulation}

In IRT, in-session interactions have a wide range of potential meanings and connections to the case formulation. An IRT formulation is centered on internalized relationships with IPIRs (including wishes and fears about them in particular) and involve patterns that may or may not emerge in a given therapeutic moment. When they do, they are detectable as copy process.

In our view, the SASB-coded pattern in this passage provided by Westerman does not have obvious relation to the specific symptom-linked patterns in Sharon's IRT formulation. It relates to her IRT formulation in some ways, but only partially. Overlap includes that Sharon eventually receives input from her therapist that is reminiscent of her symptom-linked pattern involving complex messages of Blame, Protect, and Ignore (see Table 1 of that paper). We do not see her respond in the prototypic manner linked to her symptoms. She instead tries to rely on her therapist rather than giving up, sulking, or distancing herself. She may eventually produce 
her prototypic, maladaptive coping responses if the alliance rupture in this segment is maintained. Our expectation then would be that her symptoms would also appear more obviously in the session (anger, guilt, anxiety), as a pattern of Recapitulation would be played out fully in the therapy process. Instead, in the segment provided we see the therapist as adding "noise" into the system by engaging in a non-complementary (and non-collaborative) response of withholding his input.

The second major theme we summarized for Sharon (see Table 1 of our previous paper) may have greater relevance to the illustrative transcript segment. In this part of her IRTformulated pattern, Sharon is in a caregiving role for others (especially her father, and Jeff). It seems possible that Sharon (implicitly) sees herself in the role of a trusting other person (like her father and Jeff) when she interacts with her therapist. She may wish for, or expect, to receive the kind of input she typically tries to offer others when she is (more prototypically) in the caregiving role herself. She may want him to meet her needs, monitor and worry over her as she would do with others. If this view checked out with Sharon, it could potentially be recognized as a Red way of approaching her therapist. However, the therapist resists taking on a caregiver role, and the topic of Sharon's help-seeking is not explored with the IRT formulation in mind.

\section{Comparing Specific Formulation-Based Wishes}

It is interesting to return to discussion of how wished-for responses for Sharon in Interpersonal Defense Theory may link to Gift of Love wishes relative to IPIRs in IRT. The Input $>$ Response $>$ Impact on Self slide in the IRT formulation traces her proposed Red patterns. For Sharon, if we formulated a prototypic wished-for response, it might be something like: key internalized attachment figures (i.e., her IPIRs) would show concern, compassion, and take steps to help and protect her in an effective and uncomplicated way; and that she in turn could help, protect, and take good care of them. This description mainly falls in the AG region of the SASB model. When Sharon is in Red states her wishes appear to involve others complying or agreeing with her. For example, she wanted Jeff to comply by going to therapy, and broke up with him when he didn't do this. We also see that in our original formulation of Sharon, we used the word "wish" in another context that involved Sharon wanting distance from her father when his protection was perceived as intrusive or overbearing. Each of these possibilities is different from the wish formulated via Interpersonal Defense Theory to be free in the sense of being encouraged or affirmed by others to be herself. The differences bring our curiosity back to which specific elements were used to determine Sharon's wish via Interpersonal Defense Theory, and how they were selected from among alternatives.

From an IRT point of view, Sharon's wishes are ultimately that her internalized family in the head would show concern and compassion, and thus make up to her what we infer was painfully missed out on in her earlier development. In certain states, Sharon might wish that other persons in the present might provide this input, but an IRT lens suggests her "family in the head" is in dialogue with her yearnings and so runs the motivational programming. Paradoxes can occur. Sharon may engage in maladaptive patterns with others so as to get her wish met by the internalizations for behaving according to their rules for her, rather than seeking to get the same needs met by current persons in the here-and-now. For example, if one of the more 
speculative aspects of our formulation for Sharon is correct, then when Sharon keeps herself from moving on and engaging in new relationships she keeps herself in proximity to her father as a GOL to him, and seeks his approval and validation for doing so.

\section{COMPARING IMPLICATIONS FOR TREATMENT}

\section{Comparing Treatment Implications in General}

As noted previously, IRT is an approach to treatment that contains a variety of propositions about how change takes place. Tailoring and applying IRT principles is anchored in use of the case formulation across multiple therapy steps and stages of change outlined briefly in our formulation of Sharon (for full elaboration, see Benjamin, 2003/2006; 2018). The IRT formulation is thus a key component of a specific, organized approach to treatment, rather than only having "implications" in a more distanced way.

\section{$\underline{\text { Points of Connection }}$}

A general point of connection between IRT and Interpersonal Defense Theory is that awareness of patterns has the potential to bring about new ways of choosing. Each approach generally empowers clinicians to use whatever techniques might help. For both approaches, change can occur through in-session processes such as the corrective emotional experience of having an interaction go well with a therapist in a way that defies old templates and invites an updating of wishes, fears, and strategies for navigating them. It can also occur through deliberate choice and practice with not repeating old patterns outside of sessions, replacing them with healthier alternate behaviors, thoughts, and feelings.

\section{$\underline{\text { Departures }}$}

Therapy Goals. Westerman (2021a) notes that "from the vantage point of Interpersonal Defense Theory, the goal of therapy is to help people move from defensive to nondefensive ways of negotiating wish-fear conflicts." By contrast, therapy goals in IRT are anchored in positions on the SASB model as they apply to specific relational contexts, rather than to the presence of defense. As discussed previously, we believe that interpersonal defenses can sometimes have adaptive uses. In IRT, the goal involves interactions in normative relationships (including with the self) that have a baseline of AG behaviors. This can include getting psychological distance from toxic figures (internalized or otherwise) when necessary to facilitate that baseline. It also means responding appropriately and effectively to realistically appraised threats.

As discussed already, the approach holds that at least some forms of interpersonal and intrapsychic defense can be healthy and adaptive. If we understand Interpersonal Defense Theory correctly, wishes and fears have potential to occur anywhere around the SASB structure and so nondefensive sequences could in theory involve wishes that are outside of AG behaviors, or fears that are inside of the AG region. These configurations would go against our earlier discussion of normal versus pathological uses of defense (Benjamin, 1995). Clinical symptoms and problems are expectable when wishes and fears are not oriented on the SASB model to produce an AG baseline of relating. 
K.L. Critchfield, J. Dobner-Pereira, \& E. Stucker

Pragmatic Case Studies in Psychotherapy, http://pcsp.libraries.rutgers.edu

Volume 17, Module 1, Article 6, pp. 85-103, 04-19-21 [copyright by authors]

Object of Wishes and Fears. As noted earlier, a key distinction between theories relates to decision-making about therapeutic focus: specifically, to whom do the salient wishes and fears refer? If Sharon engages in an argument with a current partner that precisely parallels how her parents fought, the IRT view is that this needs to be understood on at least two levels of analysis: (1) she has a problem in the present that needs resolution and likely involves patterns of complementarity, wishes, fears, cognitions, affects, and so on that relate to the current partner, and (2) the argument may also represent a problematic way of gaining wished-for proximity to her early attachment figures: it may feel familiar; it may also represent a desire to make things right in the parental relationship in the past. Both levels of motivation and perception are undoubtedly important to track and to formulate when present. Self-treatment may also be relevant. What is less clear to us is whether wishes and fears related to the therapist should have the same priority in terms of their salience relative to presenting problems.

Clarity of Links to Symptoms and Symptom Change. Related to the above point, the methods diverge in terms of how, or whether, a focus on wishes and fears are key leverage points for bringing about change in presenting problems and symptoms. Benjamin (2018) emphasizes the mechanisms by which attachment-based learning is encoded by the nervous system at the level of safety and threat responses in relation to contextual cues. When safety and threat are significantly miscued, problems with adaptation result in later developmental periods. Therapeutic change can be thought of as a process of re-cuing the safety and threat system. Resolution of the GOL is sometimes transformative in and of itself. However, the process of change usually involves considerably more. Change often entails learning new patterns and practicing specific skills of being (thinking, feeling, relating with self and others) once the motivational issues (linked to wishes and fears, including the GOL) are addressed and the patient gains internal permission to defy the IPIRs by adopting concrete changes.

\section{Comparing Treatment Implications for Sharon's Case}

Both the Interpersonal Defense Theory and IRT formulations agree that Sharon's therapist intervenes in ways that will not be helpful. Westerman (2021a) illustrates how the therapist contributes to problematic communication patterns and does not draw effective attention to them or to their putative underlying wishes and fears. While we did not SASB code the entire passage provided by Westerman, we agree that the therapist becomes more enmeshed (i.e., lower on the SASB model) and more hostile as the interaction proceeds.

From an IRT point of view, the therapist is also non-adherent to the case formulation and to IRT's principles of change. We did not conduct formal adherence ratings, but we had the opportunity to informally review a number of sessions while on our primary quest for interpersonal details about Sharon's family history and patterns outside of therapy. What we observed was that the therapist recurrently intervened in ways that either dismissed the relevance of Sharon's history, or were now aligned with how she reported her experiences. He courted copy process re-enactments and contributed to alliance ruptures by offering forms of interpersonal hostility, usually in a complex manner alongside helpful-sounding (but we believe often inaccurate) interpretations of the transference relationship. Some of this process is shown in the transcript segment offered by Westerman. 
K.L. Critchfield, J. Dobner-Pereira, \& E. Stucker

Pragmatic Case Studies in Psychotherapy, http://pcsp.libraries.rutgers.edu

Volume 17, Module 1, Article 6, pp. 85-103, 04-19-21 [copyright by authors]

Our approaches would not be unusual in concluding that a negative outcome is predicted based on presence of interpersonal hostility as an index of a poor alliance (Henry, Schacht, \& Strupp, 1986; 1990) and inaccurate use of transference interpretation (Crits-Christoph et al., 2010). The former issue is understood to be a common factor across treatment approaches. The accuracy issue requires a careful history and formulation to assess.

A more detailed critique of the therapist's process is illustrated in the SASB codes we provided earlier. To summarize the parts of the therapist's actions that we found problematic: when asked to provide input about what appeared to be a reasonable therapeutic topic, Sharon's therapist withheld it, shifted focus and ultimately offered a critique of Sharon for asking in the first place. His contribution to her process included a complex blend of behaviors that included Blame and Ignore. ${ }^{2}$ Since Sharon reported leaving two prior therapies with a sense that she was not being heard and that her concerns and feelings about Jeff were not addressed, this process seems to be headed down a familiar road to treatment failure.

We also agree with Westerman that for the transcript segment provided, the therapist could have, and likely should have, responded to Sharon's request for input with: "Oh, you're suggesting that Jeff was trying to hurt you. I think you might be right. What do you think about Jeff doing that?" or something similar. We agree this would be the antidote, but emphasize different reasons than does Westerman. At the level of sequential process, this approach would provide a friendly response that does not ignore context. Whether or not the therapist's response is wished for or feared, this response would fall into the AG region for interacting. It would have the advantage of being responsive to proximal patient needs (Kramer \& Stiles, 2015; Critchfield et al., 2018). It would also be consistent with the normative interpersonal stance associated with positive outcomes across psychodynamic/interpersonal, cognitive-behavioral, and existential/humanistic forms of treatment inspected to date using the SASB model (Critchfield, Henry, Castonguay, \& Borkovec, 2007; Wong \& Pos, 2014).

From an IRT point of view, it would also have the advantage of steering directly into a key attachment relationship identified in the current and prior two therapies (i.e., ex-fiancé Jeff). Such a response, at least in the moment, would be much more adherent to IRT principles at the level of what content is brought into focus. Unfortunately, Sharon remains centered on Jeff while the therapist misaligns with her by attempting to interpret patterns in their transference relationship.

\section{Overlap and Difference Regarding Putative Mechanisms of Change}

Both Interpersonal Defense Theory and IRT formulations are clear that the interpersonal stance and themes discussed by Sharon's therapist should not lead to therapeutic change. However, we diverge in terms of what mechanisms might be most important for linking insession process to eventual outcome.

As noted previously, Interpersonal Defense Theory is focused primarily on wished-for and feared states, and the defenses that maintain or block these states particularly within the therapeutic relationship. For Sharon, the Interpersonal Defense Theory formulation notes how her behavior is incompatible with wished for states since it pulls for control and a lack of warmth 
from her therapist. Related treatment suggestions involve helping her to become aware of and shift this pattern.

IRT is also concerned about wishes and fears as well as sequential relational processes. However, the IRT view addresses what might be thought of as a different layer of Sharon's wishes and fears. For her, these reflect a history with loved ones that involves being simultaneously controlled and neglected, and in turn links through copy process to her presenting symptoms. Deeper inspection as to why or how those patterns (including associated wishes and fears) have come to be would be used to enhance awareness and then to press for change at the level of attachment wishes that drive patterns.

\section{CONCLUDING COMMENTS}

Overall, we see areas of alignment, but also divergence when comparing formulations derived from Interpersonal Defense Theory and IRT. The two methods share a great deal in terms of assumptive worldviews, prioritization of relational material, and even specific methodology (SASB). Where the methods diverge, we believe it is because they each seek answers to different kinds of questions. Each approach organizes and inspects clinical materials according to its own area of central concern.

\section{Possible Bridging Between Interpersonal Defense Theory and IRT}

It is possible that a reconciled language about wishes and fears could help build additional connections between theories. For example, IRT invokes the language of wish and fear at a few different levels of analysis. The "deepest" level involves internalized attachment relationships that are active in the present, for which the concept of GOL is invoked. At other levels of analysis, Benjamin has described prototypic wishes and fears for each of the DSM-IV/5 personality disorders (Benjamin, 1993/1996) as well as with regard to interpersonal and intrapsychic defenses along a range of normal/adaptive to pathological/maladaptive functioning (Benjamin, 1995). The IRT formulation allows a fair amount of narrative flexibility around these topics and levels of analysis, mainly emphasizing what was learned or internalized that repeats in problem-linked ways now. In addition, separate constellations of wish and fear can be articulated for different parts of the self, Red and Green.

Both formulation perspectives, including their levels of analysis, have potential implications within the conceptual space defined by the other. This may be where conceptual bridges involving mechanisms of psychopathology maintenance and change could be explored, especially given the shared language system provided by SASB. For example, from an IRT point of view, it seems that interpersonal defense phenomena may be used to cue therapists to potential activation of copy process patterns. Recognition of copy process patterns could then be addressed for their implications in the present and/or used to invoke thoughts and feelings about the related attachment figures whose protection, love, or approval are also being sought in those moments.

\section{$\underline{\text { A Unifying Meta-Theoretical Frame }}$}


A unified model of psychotherapy integration (Critchfield, Mackaronis, \& Benjamin, 2017; Magnavita \& Anchin, 2014) suggests that work to differentiate and respectively position these particular approaches within some larger model of human relational behavior may be possible. Interpersonal Defense Theory brings a set of helpful perspectives about ways in which sequential coordination of relational patterns can be driven by deeper motivations to produce personality dysfunction. IRT links these areas of miscuing to prior relational history and provides clinicians tools to recognize en vivo re-enactments of copy process patterns in session that may mirror or inform relating outside the session. It seems to us that the process of trying to align the languages of Interpersonal Defense Theory and IRT invokes a set of underlying principles about human nature that may prove to be of general utility for patients and therapists alike.

\section{REFERENCES}

Benjamin, L. S. (1993/1996). Interpersonal diagnosis and treatment of personality disorders. New York: Guilford Press.

Benjamin, L. S. (1995). Good defenses make good neighbors. In H. R. Conte \& R. Plutchik (Eds.). Ego defenses: Theory and measurement (p. 53-78). John Wiley \& Sons.

Benjamin, L. S. (2003/2006). Interpersonal reconstructive therapy. The Guilford Press.

Benjamin, L. S. (2018). Interpersonal reconstructive therapy for anger, anxiety, and depression: It's about broken hearts, not broken brains. American Psychological Association. https://doi.org/10.1037/0000090-000.

Benjamin, L. S., \& Cushing, G. (2000). Reference manual for coding social interactions in terms of structural analysis of social behavior. Salt Lake City, UT: University of Utah.

Conroy, D. E., \& Pincus, A. L. (2006). A comparison of mean partialing and dual-hypothesis testing to evaluate stereotype effects when assessing profile similarity. Journal of Personality Assessment, 86, 142-149. http://dx.doi.org/10.1207/s15327752jpa8602 03.

Critchfield, K. L., \& Benjamin, L. S. (2006). Principles for psychosocial treatment of personality disorder: Summary of the APA Division 12 Task Force/NASPR review. Journal of Clinical Psychology, 62, 661-674. https://doi.org/10.1002/jclp.20255.

Critchfield, K. L., \& Benjamin, L. S. (2008). Internalized representations of early interpersonal experience and adult relationships: A test of copy process theory in clinical and nonclinical settings. Psychiatry, 71, 71-92. http://dx.doi.org/10.1521/psyc.2008.71.1.71.

Critchfield, K. L., \& Benjamin, L. S. (2010). Assessment of repeated relational patterns for individual cases using the SASB-Based Intrex Questionnaire. Journal of Personality Assessment, 92, 480-489. http://dx.doi.org/10.1080/00223891.2010.513286.

Critchfield, K. L., \& Benjamin, L. S. (2019, June). Mechanisms and processes of change in Interpersonal Reconstructive Therapy for CORDS patients. Paper presented to the Society for Exploration of Psychotherapy Integration, Lisbon, Portugal.

Critchfield, K. L., Benjamin, L. S., \& Levenick, K. (2015). Reliability, sensitivity, and specificity of case formulations for comorbid profiles in interpersonal reconstructive therapy: Addressing mechanisms of psychopathology. Journal of Personality Disorders, 29(4), 547-573. https://doi.org/10.1521/pedi.2015.29.4.547. 
K.L. Critchfield, J. Dobner-Pereira, \& E. Stucker

Pragmatic Case Studies in Psychotherapy, http://pcsp.libraries.rutgers.edu

Volume 17, Module 1, Article 6, pp. 85-103, 04-19-21 [copyright by authors]

Critchfield, K.L., Dobner-Pereira, J., \& Stucker, E. (2021a). The case of Sharon considered from the vantage point of Interpersonal Reconstructive Therapy. Pragmatic Case Studies in Psychotherapy, 17 (1), Article 4, 42-62. Available: http://pcsp.libraries.rutgers.edu/

Critchfield, K. L., Henry, W. P., Castonguay, L. G., \& Borkovec, T. D. (2007). Interpersonal process and outcome in variants of cognitive-behavioral psychotherapy. Journal of Clinical Psychology, 63, 31-51. doi:10.1002/jclp.20329

Critchfield, K. L., Mackaronis, J. E., \& Benjamin, L. S. (2017). Integrative use of CBT and Psychodynamic techniques in Interpersonal Reconstructive Therapy. Journal of Psychotherapy Integration, 27(4), 460-475. http://dx.doi.org/10.1037/int0000092.

Critchfield, K. L., Panizo, M, T., Dobner-Pereira, J., Drucker, K. (2018). Beyond the Borderline: Expanding Our Repertoire to Address Relational Patterns and Power Dynamics Attendant to Diverse Personality Disorders. Journal of Contemporary Psychotherapy, 49(1), 61-67. https://doi.org/10.1007/s10879-018-9409-8

Critchfield, K. L., Stucker, E. I., Bonilla, K., Mischinski, M., \& Benjamin, L. S. (May, 2020). Exploring differential therapist responsiveness to attachment-based mechanisms of change in Interpersonal Reconstructive Therapy. Poster presented to the Society for Exploration of Psychotherapy Integration, virtual online poster session.

Crits-Christoph, P., Gibbons, M. B. C., Themes, C. M., Elkin, I., \& Gallop, R. (2010). Interpersonal accuracy of interventions and the outcome of cognitive and interpersonal therapies for depression. Journal of Consulting and Clinical Psychology, 78, 420-428. doi:10.1037/a0019549

Dahl, H. (1995). An information feedback theory of emotions and defenses. In H. R. Conte \& R. Plutchik (Eds.). Ego defenses: Theory and measurement (p. 98-119). John Wiley \& Sons.

Henry, W. P., Schacht, T. E., \& Strupp, H. H. (1986). Structural analysis of social behavior: Application to a study of interpersonal process in differential psychotherapeutic outcome. Journal of Consulting and Clinical Psychology, 54, 27-31.

Henry, W. P., Schacht, T. E., \& Strupp, H. H. (1990). Client and therapist introject, interpersonal process, and differential psychotherapy outcome. Journal of Consulting and Clinical Psychology, 58, 768-774.

Horowitz, M.J., and Stinson, C.H. (1995). Defenses as aspects of person schemas and control processes. In Conte, H., and Plutchik, R. (eds). Ego Defenses: Theory and Measurement, pp. 79-97. 1994.

Karpiak, C. P., \& Benjamin, L. S. (2004). Therapist Affirmation and the Process and Outcome of Psychotherapy: Two Sequential Analytic Studies. Journal of Clinical Psychology, 60(6), 659-676. https://doi.org/10.1002/jclp.10248

Kramer, U., \& Stiles, W. B. (2015). The responsiveness problem in psychotherapy: A review of proposed solutions. Clinical Psychology: Science and Practice, 22(3), 277-295. https://doi.org/10.1111/cpsp.12107.

Luborsky, L., \& Crits-Christoph, P. (1990). Understanding transference: The Core Conflictual Relationship Theme method. Washington, DC: American Psychological Association.

Magnavita, J. J., \& Anchin, J. C. (2014). Unifying psychotherapy: Principles, methods, and evidence from clinical science. New York, NY: Springer.

Strupp, H. H., \& Binder, J. L. (1984). Psychotherapy in a New Key. New York: Basic Books. 
Ulberg, R., Amlo, S., Critchfield, K. L., Marble, A., \& Høglend, P. (2014). Transference interventions and the process between therapist and patient. Psychotherapy, 51(2), 258269. DOI: $10.1037 / \mathrm{a} 0034708$.

Westerman, M. A. (2019). Case formulation in interpersonal defense theory: A process model of interpersonal phenomena that play key roles in psychopathology and psychotherapy. In U. Kramer (Ed.), Case formulation for personality disorders: Tailoring psychotherapy to the individual client (pp. 315-335). London, United Kingdom: Elsevier.

Westerman, M.A. (2021a). The case of Sharon considered from the vantage point of Interpersonal Defense Theory. Pragmatic Case Studies in Psychotherapy, 17 (1), Article 3, 19-41. Available: http://pcsp.libraries.rutgers.edu/

Westerman, M.A. (2021b). Comparing Interpersonal Defense Theory and Interpersonal Reconstructive Therapy and their views of Sharon's case. Pragmatic Case Studies in Psychotherapy, 17 (1), Article 5, 63-84. Available: http://pcsp.libraries.rutgers.edu/

Wong, K. and Pos, A. (2014) Interpersonal Processes Affecting Early Alliance Formation in Experiential Therapy for Depression. Psychotherapy Research, 24, 1-11. https://doi.org/10.1080/10503307.2012.708794

\section{ENDNOTES}

${ }^{1}$ The Full Model points identified by Westerman cross the boundary of these two clusters.

${ }^{2}$ We do not have access to the recording for this passage to fully determine whether the tone and pacing fits with our inferences. The tone of the conversation could particularly influence the degree to which hostility was present, and any potential meaning associated with their cross-talk / interruptions. To elaborate on our coding, Ignore is inferred in part through normative expectation about the roles they have with one another. Focused on Sharon, the therapist grants her autonomy in a way that we perceive as having moderate hostility because the requested input is something she cares about, is reasonable to ask in context of their work together, and that he could provide or attempt to provide. With regard to complex messages (Protect + Blame) we saw the therapist as providing a warm and structuring rationale for not responding, coupled with a moderately unfriendly critique of her help-seeking. 
K.L. Critchfield, J. Dobner-Pereira, \& E. Stucker

Pragmatic Case Studies in Psychotherapy, http://pcsp.libraries.rutgers.edu

Volume 17, Module 1, Article 6, pp. 85-103, 04-19-21 [copyright by authors]

Table 1. Divergent SASB-Based Impressions for Sharon's Transcript Segment

$\underline{\text { SASB coding (cluster model) }}$

\section{$\underline{\text { Transcript }}$}

1 S: and what do you think? (smiles)

2 Th: Well I don't know if what I think is important because/l

3 S: //(interjects) it's important (laughs)

4 Th: because you know him much better than I do//

5 S: //(interrupts) Right, but no, it's an opinion I'm just curious//

6 Th: //(interrupts) yeah, I really have no idea other than what you're telling me. You know what I mean...I think it's hard for you to make a decision

7 S: um huh (yes)

8 Th: for yourself...you know that you're um you know soliciting my opinion or your friend's opinion even though you know you really know him [S nodding] much better than anybody else.

9 S: True, but I think this just this is it's not definitive what it means so I am curious to seell

10 Th: um huh (yes, backchannel)

11 S: What other people are going to interpret as being...I mean, you're a man and if you wanted to hurt somebody umm (pause) would that be the choice of words you would use? $\underline{\text { Westerman } \quad \text { Critchfield et al. }}$

$\underline{\text { Trust }}$

Control $\underline{\text { Separate }}+$ Ignore

$\underline{\text { Separate }} \quad \underline{\text { Trust }}+$ Affirm

Control Separate + Ignore (cont.), Affirm

$\underline{\text { Submit }}{ }^{\dagger}$,

$\underline{\text { Submit, }}$ $\underline{\text { Separate }}$ $\underline{\text { Trust }}$

Protect

Separate, Protect + Blame

$\begin{array}{cc}-- & \text { Submit } \\ -- & \text { Protect }+ \text { Blame } \\ \text { (cont.), } \\ \text { Affirm }\end{array}$

$\underline{\text { Submit }^{\dagger}}$, Submit, Disclose, $\underline{\text { Separate }}$ $\underline{\text { Trust }}$

Affirm

Trust

(re: whether Jeff's letter contains

Attack)

-- code not presented;

+ complex/simultaneous code;

$\dagger$ this code reflects language of "agrees with" as described by Westerman for this unit. Note: For Westerman's codes, SASB Full Model points are replaced with their Simplified Cluster Model equivalents. 